\title{
Operation power consumption and verification tests of a trenching device for orchards in Xinjiang based on discrete element
}

\author{
Chen $\mathrm{Ma}^{1,2}$, Jiangtao $\mathrm{Qi}^{1,3}$, Za Kan ${ }^{1,3}$, Shaojie Chen ${ }^{4}$, Hewei Meng ${ }^{1,3^{*}}$ \\ (1. College of Mechanical and Electrical Engineering, Shihezi University, Shihezi 832000, Xinjiang, China; \\ 2. College of Mechanical and Electronic Engineering, Xinjiang Vocational University, Urumqi 830013, China; \\ 3. Key Laboratory of Northwest Agricultural Machinery of the Ministry of Agriculture, Shihezi 832000, Xinjiang, China; \\ 4. Ruiyida Machinery Equipment Co., Ltd., Shihezi Development Zone, Shihezi 832000, Xinjiang, China)
}

\begin{abstract}
According to the agronomic requirements of orchard planting pattern and fertilization in Xinjiang, the soil particle models and a soil-trenching device interaction model were established by using discrete element simulation software in order to find out the law of influence of structure parameters and working parameters on the operation power consumption of a segmented cutting trenching device; moreover, its cutting process was simulated according to the response surface test design. According to the results of research on the influence of forward speed, cutter disk speed and cutter disk combination on the operation power consumption of the segmented cutting trenching device, the law of their influence on the operation power consumption in descending order is forward speed, cutter disk combination, cutter disk speed. According to the response surface test result, the following influential factor parameter combination has been obtained: forward speed $815 \mathrm{~m} / \mathrm{h}$, cutter disk speed $112 \mathrm{r} / \mathrm{min}$, cutter disk combination A (cut angle $150^{\circ}$, bent angle $60^{\circ}$ and working width $133 \mathrm{~mm}$ ), cutter disk combination $\mathrm{B}$ (cut angle $180^{\circ}$, bent angle $90^{\circ}$ and working width $166 \mathrm{~mm}$ ), and trenching operation power consumption-optimization results were verified through field tests. According to the verification, the results showed a high accuracy of the simulation, with a relative error mean of $3.18 \%$ between the theoretical value and the field test value. This study can provide a reference for the energy-saving design of orchard trenching devices.
\end{abstract}

Keywords: trenching device, discrete element, orchard, power consumption, simulation analysis, parameter optimization DOI: $10.25165 /$ j.ijabe. 20211401.5477

Citation: Ma C, Qi J T, Kan Z, Chen S J, Meng H W. Operation power consumption and verification tests of a trenching device for orchards in Xinjiang based on discrete element. Int J Agric \& Biol Eng, 2021; 14(1): 133-141.

\section{Introduction}

Xinjiang has become an important "Great Western Orchard" in China due to its unique light and heat conditions and regional climate advantages. Depending on statistics, as of the end of 2019, Xinjiang's characteristic forest fruit planting area reached 935.4 thousand $\mathrm{hm}^{2}$, with a total yield of 1604.8 million $\mathrm{t}^{[1]}$. Fertilization is an important factor affecting the yield and quality of forest fruit during the planting of fruit trees. At present, deep application of organic fertilizers for orchards mainly relies on manual work, and this mode has disadvantages such as high labor intensity, low work efficiency, etc. The existing mechanical fertilization modes usually involve the adoption of plough type, uniform cutter disc type and chain cutter type trenching machinery. According to the agronomic requirements of the application of plentiful organic fertilizers, narrow planting rows, etc. in orchards in Xinjiang, the current mode of deep application of organic

Received date: $2019-10-26$ Accepted date: 2020-08-04

Biographies: Chen Ma, Master candidate, Assistant, research interest: mechanical design and theory, Email: marcia.chen@foxmail.com; Jiangtao Qi, Master candidate, Experimentalist, research interest: agricultural mechanization design and manufacture, Email: 510014078@qq.com; Za Kan, Bachelor, Professor, research interest: agricultural mechanization. Email: kz-shz@163.com; Shaojie Chen, Master candidate, research interest: agricultural mechanization, Email: 1215762364@qq.com.

*Corresponding Author: Hewei Meng, PhD, Associate Professor, research interest: organic fertilizer deep application machinery in orchard. School of mechanical and electrical engineering, Shihezi University, Shihezi 832000, China. Tel: +86-13999335390, Email: 6318687@qq.com. fertilizers in orchards easily causes problems such as insufficient trenching depth, large power consumption, multiple times of soils cutting, large equipment structure size, large difficulty in field operations, etc. Therefore, it is urgently needed to research machinery for the deep application of organic fertilizers in orchards.

In recent years, the orchard trenching machinery mainly uses disk type trenching machinery. It has advantages such as low traction resistance, high work efficiency, easy cooperation with fertilizing devices, small structure size, etc., and has gradually become mainstream machinery for the deep application of organic fertilizers and trenching in orchards ${ }^{[2]}$. A single disk trencher has a simple structure; by simply installing a cutter disk up to trench operation requirements, the single disk trencher can achieve the objective of cutting and throwing soils in the advancement process. Therefore, this study selects a single disk trencher. The trenching mechanism is the key component for mechanized fertilization, and its structure parameters and working parameters are the key to its design and directly affect the indicators such as power consumption, work efficiency, etc. in the device's production operation. Power consumption is the core of the traditional design of a trenching device, but there are problems such as large errors, the existence of certain blindness, nonconformity with the modern agricultural planning goal of "control, reduction, fundamental", etc ${ }^{[3]}$. Therefore, it is urgently needed to carry out power consumption analysis of trenching devices during operation to reduce energy consumption and cost.

Recently, simulation analysis software has made considerable progress in the field of interaction between mechanical components 
and soils. Asl and Singh ${ }^{[4]}$ analyzed the power consumption of trenching devices and optimized the parameters of three types of rotary tillage cutters by building mathematical models for dynamic and static cutting of soils with rotary tillage cutters. Ucgul et al. ${ }^{[5]}$ established a discrete element simulation model for the direct shear test, penetration test and soil shoveling test. According to the simulation results, discrete element simulation software is an effective method for studying soil-machinery interaction. Mootaz et al. ${ }^{[6]}$ carried out three-dimensional dynamic finite element analysis of tillage components and soils by pre-defining the failure surface of soils, and obtained the variation curve of cutting acceleration vs. cutting resistance. Zhu et al. ${ }^{[7-9]}$ derived the horizontal and vertical resistance equations for rotary cultivator cutters according to the law of cutting, breaking and throwing of soil with rotary cutter blades. Qin et al. ${ }^{[10]}$ analyzed and optimized the structure parameters and operating parameters affecting the power consumption of trenchers using the motion simulation technology, so that the power consumption of trenchers was reduced by $11.71 \%$. Zhang et al. ${ }^{[11]}$ designed a double-disk self-propelled trenching fertilizer applicator based on the characteristics of dwarf close planting jujube orchards; in addition, they carried out a dynamic simulation analysis of the soil cutting process of rotary tillage bent cutters on cutter disks, and studied the degree of soil damage caused by bent cutters in the cutting operation process using the finite element software ANSYS/LS-DYNA. Kang et al. ${ }^{[12]}$ probed into the influence of changes in soil physical properties and working parameters on the working efficiency of disc trenchers based on the current situation of orchard planting; in addition, they obtained the variation law of the power consumption during soil cutting with trenching bent cutters using the LS-DYNA power module in ANSYS software. Pan et al. ${ }^{[13]}$ took the opener and soil as the research object, based on this soil particle discrete element simulation model, optimized the structure parameters of the core-escape opener, and obtained the optimal parameter combination of the core-bell opener. Tian et al. ${ }^{[14]}$ established the interaction model between the soil-covering disc and the soil by using the discrete element method, and determined the relationship between the resistance of the soil-covering disc in the forward direction, the mass flow rate and the working parameters through simulation experiments. Jia et al. ${ }^{[15]}$ designed a mole imitation Platycodon grandiflorum cleaner based on the corn cultivation situation under no-tillage conditions in Northeast China, determined cleaner types using EDEM simulation software, and obtained the law of influence of parameters on cleanup quality. Lin et al. ${ }^{[16]}$ designed a straw ditching knife that imitated the front foot curve of a praying mantis, and used discrete element software for experimental verification, and obtained a regression mathematical model of straw depth and straw coverage. In summary, there is no systematic study of the structural parameters and working parameters of the trenching device at this stage, especially the trenching process under the boundary conditions of soil characteristics and orchard fertilization requirements. Therefore, it is necessary to further study the power consumption of orchard trenching operations.

When EDEM simulates the micro-macro deformation between the large-scale particle swarm system and the material of the contact device, it allows agglomeration or agglomeration breakage between discrete particles. It is also suitable for simulating the interaction between soil and rigid body, using simulation methods to obtain high efficiency and low consumption. The optimal working combination parameters of the ditching device can not only reduce the costs of physical prototype design and processing but also shorten the prototype field performance test cycle. Therefore, this study aimed that under the background of EDEM software, using discrete element EDEM simulation software to establish a soil-ditch cutter operating model to study the impact of operating parameters and parameters on operating power consumption, obtain the optimal combination of influencing factors and parameters, and conduct optimization experiments to verify through field trials. It provides a theoretical basis for the design of the deep application of organic fertilizer and trenching device.

\section{Analysis of the structure and power consumption of the trenching device}

\subsection{Structure and operating principle of the trenching device}

The device (as shown in Figure 1) is mainly composed of a cutter disc, groove cutter, traction frame, cross member, shroud assembly, cutter disc driving mechanism, and side member. Cutters are arranged alternately spirally.

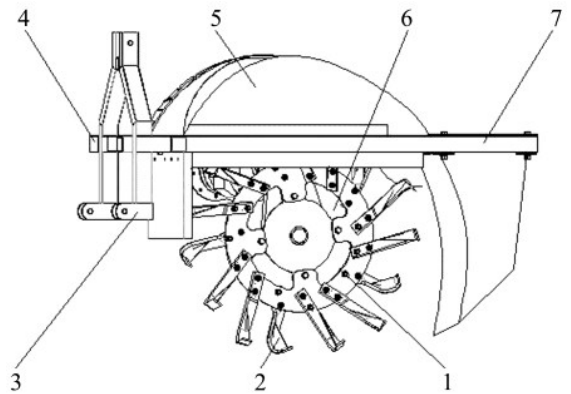

1. Cutter disk 2. Groove cutter 3. Traction frame 4. Cross member

5. Shroud assembly 6 . Cutter disk driving mechanism 7. Side member

Figure 1 Structure diagram of trenching device

The cutters are installed uniformly in the existing disc type trenching mechanism in general. A segmented cutting trenching mechanism was used based on the characteristics of soils in Xinjiang and the agronomic requirements of orchard fertilization. It consists of a cutter disk, groove cutter A and groove cutter B (as shown in Figure 2a). The main structural parameters of the cutter are soil cutting angle $\beta$, bending angle $\alpha$, working width $b$, among
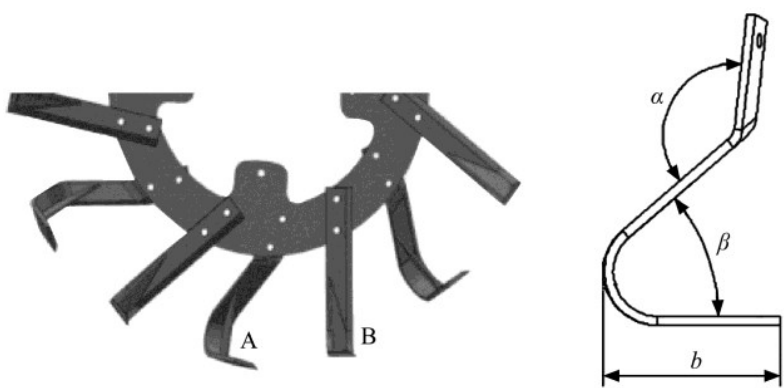

a. Cutter disc assembly

b. Structure diagram of ditching tool

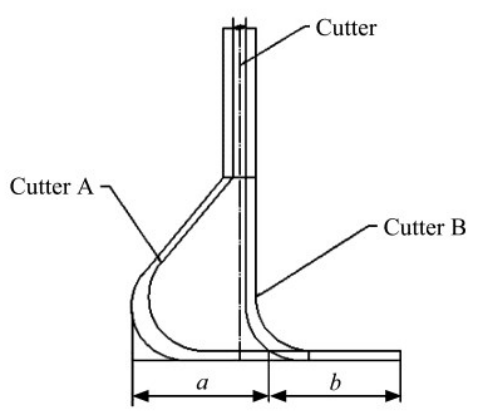

c. Schematic diagram of the same horizontal arrangement of groove cutter Figure 2 Cutter disc assembly and structure diagram of ditching tool 
which the soil cutting angle $\beta$ affects the resistance of trenching and the effect of soil crushing; the bending angle $\alpha$ affects the cutting resistance, power consumption and tool life; Working width $b$, which affects the number of cutters on the cutter roll and the rigidity of the cutter and the quality of crushed soil. The schematic diagram of the ditching cutter structure is shown in Figure $2 \mathrm{~b}$. The groove cutters $\mathrm{A}$ and $\mathrm{B}$ are arranged alternately spirally (i.e., A-B-A-B-...). The groove cutters A and B cut soils cyclically segment by segment. When the cutters are arranged on the same horizontal plane, their arrangement schematic is shown in Figure 2c. The cutters complete the trench cutting width of segments $a$ and $b$ successively (the sum of the width of the two segments is equal to the working width required by trenching), so that each groove cutter cuts soils segment by segment, and the needed working width is reached. Through the reasonable arrangement of groove cutters, they can cut soils uniformly.

\subsection{Analysis of power consumption of the trenching device}

In this paper, the element method is used to analyze the operation power consumption of the trenching device according to the alternately spiral arrangement form of groove cutters: power consumption generated during soil cutting by the cutters of the trenching device and energy conversion generated during dispersing of cut soil particles. According to the element method, the power consumption of the rotary trenching device is as follows: $W=W_{Q}+W_{P}+W_{f}+W_{T}$, where $W_{Q}$ is cutting power, $W_{P}$ is dispersing power, $W_{f}$ is the friction power consumption of collapse soils and cutter disk, and $W_{T}$ is traction power consumption. The rotary cutter disk does not generate the frictional force caused by the gravitational radial component and a gravitational tangential component due to inclination, so the frictional power consumption and traction power consumption of collapsed soils and the cutter disk are removed, and the power consumption of the rotary trenching device is $W=W_{M}+W_{P}$.

\subsubsection{Power consumption of soil rotating torque}

To analyze the cutting operation of the trenching cutter disk, it is assumed that broken soils are continuous and each of the trenching cutters cuts and throws soils uniformly and continuously. According to the Bernatka theory ${ }^{[17]}$, it is deemed that the power consumption of soil rotating torque with the cutter disk is the sum of the power consumption of soil cutting and the power consumption of the cut soils on the cutter disk. Therefore, taking the soils cut by the trenching cutter disk in the unit time $t$ as the particle system, the torque applied on the particle system is the total torque $M_{Z}$ of the cutters to the cut soils ${ }^{[18]}$. Apply the moment of momentum of the particle system to the cut soils on the cutters on $Z$-axis to obtain,

$$
\frac{\mathrm{d} L_{Z}}{\mathrm{~d} t}=M_{Z}
$$

Calculate the change $\mathrm{d} L_{Z}$ in the moment of momentum of soil particle flow within the time of $\mathrm{d} t$. Assuming that the cut soil particles are continuously stable, the change in the moment of momentum of soil particle flow within the time of $t$ is below:

$$
\mathrm{d} L_{Z}=\rho\left(v_{m} d t \cdot H \cdot B^{\prime}\right) \omega r_{i}^{2}=\rho \omega H B^{\prime} v_{m} r_{i}^{2} \mathrm{~d} t
$$

Substitute Equation (1) into Equation (2) to obtain the torque applied by cutters on the soil particle flow system as follows:

$$
M_{z}=\rho \omega H B^{\prime} v_{m}\left(\frac{R-H}{2}\right)^{2}
$$

The power consumption $W_{M}$ of rotating torque is as follows:

$$
W_{M}=\int \rho \omega^{2} H B^{\prime} v_{m}\left(\frac{R-H}{2}\right)^{2} \mathrm{~d} t
$$

where, soil density $\rho, \mathrm{kg} / \mathrm{m}^{3}$; trenching depth $H$, m; working width $B, \mathrm{~m}$; cutter disk angular velocity $\omega, \mathrm{rad} / \mathrm{s}$; unit forward speed $v_{\mathrm{m}}$, $\mathrm{m} / \mathrm{s}$; cutter disk radius of gyration $R, \mathrm{~m}$; the distance of the center of gyration of soil particles on cutters $r_{i}, \mathrm{~m}$.

\subsubsection{Power consumption of soil throwing}

The power consumption of soil throwing during trenching is mainly generated by throwing of soil particles. Assuming that the motion of thrown soils is inclined throwing motion, the initial velocity is approximated to $v_{0}$, and the influence of air resistance is neglected, according to the mechanics conservation theorem, the kinetic energy consumption of soil particles is equal to the power consumption of soil throwing; based on the theorem of kinetic energy, the following equation is obtained:

$$
\mathrm{d} W_{p}=\frac{1}{2} v_{0}^{2} \mathrm{~d} m
$$

The soil mass $\mathrm{d} m$ can be expressed as follows using parameters:

$$
\mathrm{d} m=\frac{\gamma}{g} B S \sin \sigma \mathrm{d} s
$$

Combine Equations (5) and (6) to obtain the expression of the power consumption of soil throwing:

$$
W_{p}=\int \frac{\gamma}{2 g} v_{0}^{2} B S R \sin \sigma \mathrm{d} \sigma=\int \frac{\gamma}{2 g} v_{0}{ }^{2} \omega B S R \sin \sigma \mathrm{d} t
$$

where, $\gamma$ is soil bulk density, $\mathrm{kg} / \mathrm{m}^{3} ; g$ is the acceleration of gravity, $9.8 \mathrm{~m} / \mathrm{s}^{2} ; v_{0}$ is the velocity at which the soil particles have just left cutters, $\mathrm{m} / \mathrm{s} ; S$ is bite length, $\mathrm{m} ; \sigma$ is the initial rotation angle of soil furrow slices of the cutter's soil cutting unit, $\left({ }^{\circ}\right)$; $\mathrm{d} S$ is soil unit length, $\mathrm{d} S \approx R \mathrm{~d} \sigma$.

2.2.3 Establishment of the theoretical model for operation power consumption

Combine Equation (4) with Equation (7) to obtain the operation power consumption of the trenching device:

$$
W=W_{M}+W_{P}=\int \rho \omega^{2} H B^{\prime} v_{m}\left(\frac{R-H}{2}\right)^{2} \mathrm{~d} t+\int \frac{\gamma}{2 g} v_{0}^{2} \omega B S R \sin \sigma \mathrm{d} t
$$

In the China Soil Database and the Rotary Disk Trencher ${ }^{[19]}$, the density of heavy soils is $\rho=2.65 \times 10^{3} \mathrm{~kg} / \mathrm{m}^{3}$, and the soil bulk density is $\gamma=(1.0-1.5) \times 10^{3} \mathrm{~kg} / \mathrm{m}^{3}$; According to the posterior part of the paper, the parameters of the trenching device are set as follows: $n=110 \mathrm{r} / \mathrm{min}$ and $v=0.8 \mathrm{~km} / \mathrm{h}$ for the trenching cutter disk; working width $B=30 \mathrm{~cm}$, cutter disk radius of gyration $R=60 \mathrm{~cm}$, and acceleration of gravity $g=9.8 \mathrm{~m} / \mathrm{s}^{2}$; In Equation (8), $\omega=2 \pi n$ and $S=v m \mathrm{~d} t$. Substitute the known values into Equation (8), and it was transformed and programmed using MATLAB int function, and the trenching power consumption of $19.52 \mathrm{~kW}$ was obtained through derivation.

\section{Simulation analysis of soil-trenching device interaction}

\subsection{Soil-trenching device modeling}

The cutter disk assembly is one of the important components of the trenching device for the deep application of organic fertilizers and consists of cutter disk and groove cutters. The components that affect the simulation efficiency such as frame, shroud, driving mechanism, etc. were simplified, and the connecting parts such as bolts, gaskets, nuts, etc. were ignored in the simulation in this paper. The 3D model of the cutter disk was built using SolidWorks2016 software and imported into EDEM2017 software in the format of .igs. The diameter $D$ of the cutter disk is $1200 \mathrm{~mm}$, the bent angle $\alpha$ is $40^{\circ}-90^{\circ}$, the cut angle $\beta$ 
is $130^{\circ}-180^{\circ}$, the bending radius $r$ is $50 \mathrm{~mm}$, the cutting-edge angle of the front cutting surface $i$ is $15^{\circ}$, and the working width $b$ is 90-190 mm.

\subsubsection{Soil particle model}

The soil samples used for the test were collected from Wugong Village, Shihezi City, Xinjiang Region. The average soil hardness at the soil depth of $400 \mathrm{~mm}$ measured with an SC900 soil firmness meter is $2.16 \mathrm{MPa}$; the average soil moisture content measured with a TDR300 soil moisture meter is $10.64 \%$. Referring to the China Soil Database ${ }^{[20]}$ according to the data, it can be concluded that the soils of the test site are light alkaline desert soils and the soils in the $0-50 \mathrm{~cm}$ layer are heavy soils and have blocky structure and high hardness. In order to accurately simulate the mechanical stress of soil particles under mechanical action, the Hysteretic Spring contact model was selected according to the test soil type. Based on this, four soil particle models were established: single-sphere particle model, double-sphere particle model, three-sphere particle model, and horizontal three-sphere particle model. To simulate the truer soil properties, the physical radius of particles was randomly set. In addition, too small particle diameter will increase the amount of computer operation ${ }^{[21]}$. Therefore, the physical radius of the soil was taken as $10 \mathrm{~mm}$.

3.1.2 Soil-cutter disk model

The cutting mode of the cutter disk and boundary condition processing requirements was considered in the establishment of the soil-cutter disk model in this study. The soil simulation model was set as a $1500 \mathrm{~mm} \times 2000 \mathrm{~mm} \times 600 \mathrm{~mm}$ uncovered cuboid. The cuboid was set as soil particles and generated $1.8 \times 10^{6}$ soil particles to simulate the soil environment for trenching and cutting and define the forward speed and rotation speed of the cutter disk in line with the test.

The model of soil-cutter disk interaction is indicated in Figure 3. The EDEM simulation parameters include material parameters and contact parameters. The simulation material parameters include soil density, cutter disk density, Poisson ratio, and shear modulus. The contact parameters include the coefficient of restitution between soils, coefficient of restitution between soils and cutter disk, coefficient of static friction, and coefficient of kinetic friction. The parameters were determined in this study using the method of combining experiments in references [22-25].

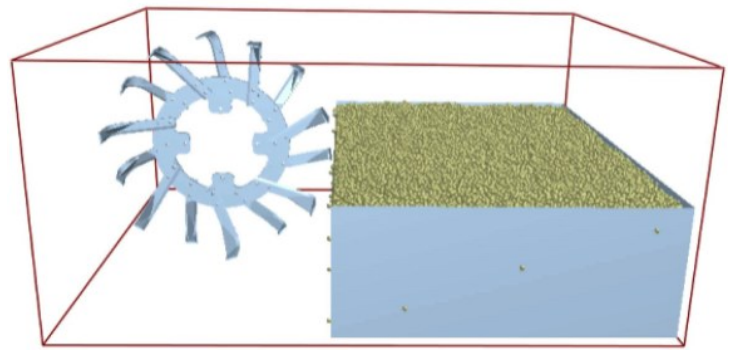

Figure 3 Model of soil-cutter disk interaction

The time step set during the test was $1 \times 10^{-6} \mathrm{~s}$. The values of the main simulation parameters are shown in Table 1 .

Table 1 Simulation parameters

\begin{tabular}{ccc}
\hline Item & Property & Value \\
\hline \multirow{3}{*}{ Soil particles } & Poisson ratio & 0.26 \\
& Shear modulus $/ \mathrm{Pa}$ & $2 \times 10^{7}$ \\
& Density $/ \mathrm{kg} \cdot \mathrm{m}^{-3}$ & 2650 \\
\hline \multirow{3}{*}{ Cutter disk } & Poisson ratio & 0.3 \\
& Shear modulus $/ \mathrm{Pa}$ & $7.99 \times 10^{10}$ \\
& Density $/ \mathrm{kg} \cdot \mathrm{m}^{-3}$ & 7800 \\
\hline
\end{tabular}

\begin{tabular}{ccc}
\hline \multirow{3}{*}{ Soil-Soil } & Coefficient of restitution & 0.532 \\
& Coefficient of static friction & 0.25 \\
& Coefficient of kinetic friction & 0.4 \\
\hline \multirow{3}{*}{ Soil-cutter disk } & Coefficient of restitution & 0.3 \\
& Coefficient of static friction & 0.5 \\
& Coefficient of kinetic friction & 0.01 \\
\hline
\end{tabular}

\subsection{Cutting simulation process}

3.2.1 Analysis of cutting process

When the trenching depth is more than $300 \mathrm{~mm}$, the motion displacement of soils in a trench can be shortened using the counterclockwise cutting method, the operation power consumption can be reduced, and the dispersing direction of the cut soils is favorable for the trenching process. Therefore, the counterclockwise cutting method was used for the cutter disk in this study. According to the coordinate system of the cutting simulation model, the working conditions of the cutter disk are described as follows: the cutter disk advances in the negative $X$-direction and cuts soils counterclockwise, as shown in Figure 4.

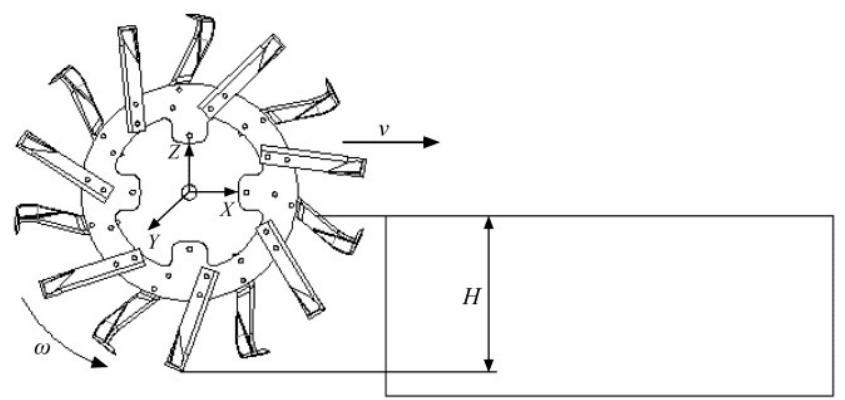

Figure 4 Working diagram of cutter disk

The cutter disk is rotated counterclockwise at $n=110 \mathrm{r} / \mathrm{min}$ and $v=0.8 \mathrm{~km} / \mathrm{h}$ to cut soils. Figure 5 is the schematic diagram of the cutter disk and soil groove cutting process. The Geometry Bin area is established using the Setup Selection function and the color of the pressure on soil particles is set using Selections. As the cutter disk rotates, the forward cutting edges of groove cutters will contact soils (Figure 5a); soils are squeezed above the lateral cutting edges of groove cutters, and the squeezed soils are broken along the forward direction of cutters (Figure 5b); afterward, under the double actions of lateral cutting edges and front cutting edges of cutters, the broken soils are rotated counterclockwise along with the cutter disk, and thrown out backward with the soil throwing plate (Figure 5c); the cut soils tend to move up along the groove cutter, proving that the cutter has a vertical pushing effect on soils in the actual operation process. During simulation operation for $0.2 \mathrm{~s}$, the adjacent groove cutters begin cutting, and the two types of groove cutters $A$ and $B$ cut soils alternately spirally segment by segment to achieve the working width according to agronomic requirements (Figures $5 \mathrm{~d}$ and $5 \mathrm{e}$ ). Due to being limited by the test and study, the shroud affecting the simulation efficiency was simplified, so soil backflow was serious during the simulation.

\subsubsection{Analysis of power consumption in the cutting process}

According to the principle of theoretical mechanics, the relation of the operation power consumption $P$ with the torque $T$ and the speed $n$ in the process of soil cutting of the groove cutter is as follows:

$$
P=\frac{T \cdot n}{9550}
$$

where, $P$ is the power consumption in the cutting process, $\mathrm{kW}$; $T$ is power output torque, $\mathrm{N} \cdot \mathrm{m} ; n$ is cutter disk speed, $\mathrm{r} / \mathrm{min}$. 

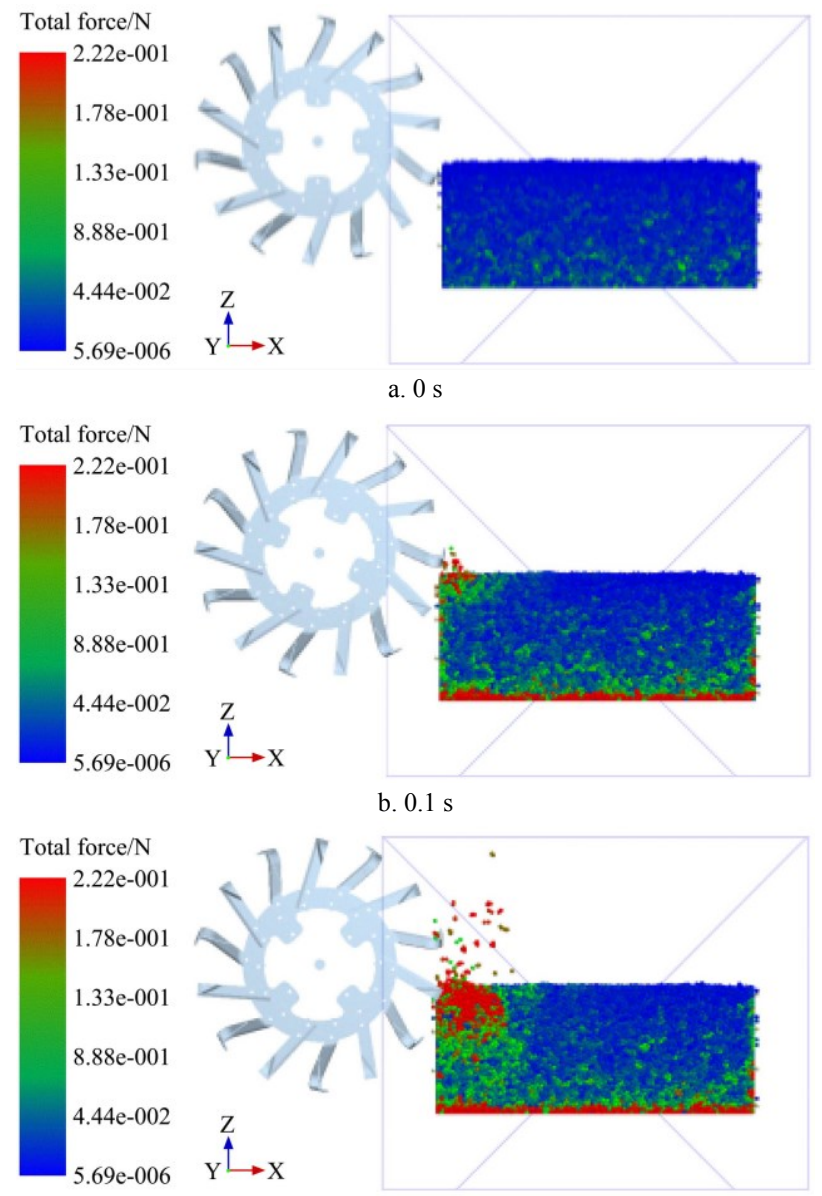

c. $0.2 \mathrm{~s}$

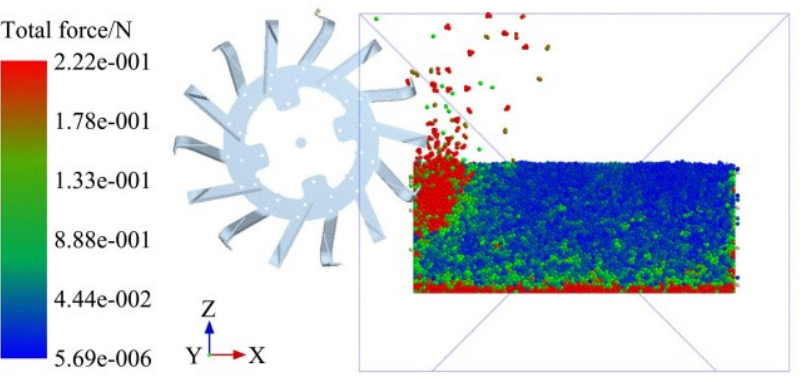

d. $0.3 \mathrm{~s}$

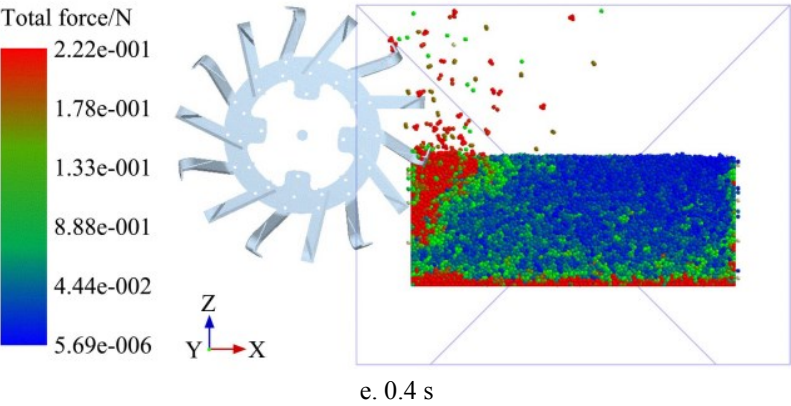

Figure 5 Cutter disk and soil groove cutting process diagram

Therefore, the operation power consumption in the cutting process can be calculated only needing to measure the torque and speed of the cutter disk. The power consumption variation in the cutting process is shown in Figure 6. Operation power consumption gradually increases with time in the early stage of soil cutting by the cutter disk. This is because the cutter disk continuously advances and finally completely enters the soil groove during soil groove cutting; in addition, as the cutter disk rotates and advances, the trenching depth increases gradually, the soil extrusion force on the cutter increases during cutting, and the total power consumption of the cutting tends to increase gradually. When the cutting time is from $0 \mathrm{~s}$ to $3.6 \mathrm{~s}$, and the operation power consumption gradually increases from $0 \mathrm{~kW}$ to $18.87 \mathrm{~kW}$. After simulation operation for $3.8 \mathrm{~s}$, the operation power consumption of the cutter disk fluctuates to a small extent but tends to be stable on the whole because of reduced contact force between soil particles after being broken.

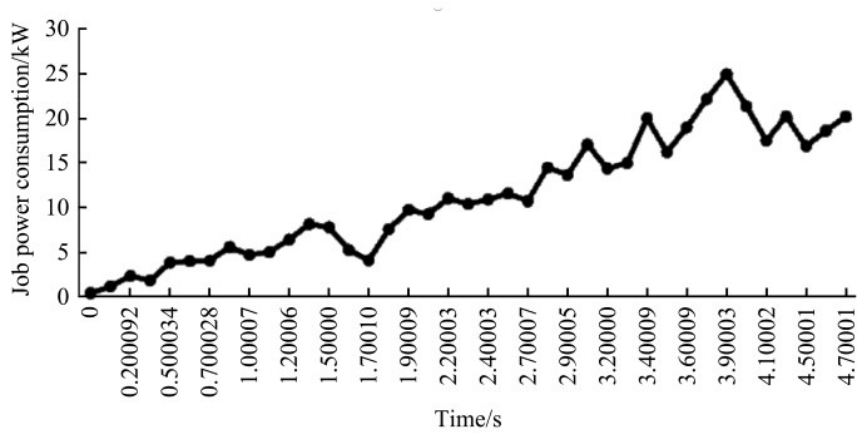

Figure 6 Power consumption curve of cutting process

\subsection{Simulation test design}

In order to study the influence of different structure parameters and working parameters on the power consumption variation of the cutter disk, forward speed, cutter disk speed and three sets of cutters with different structure parameters are selected as investigation factors and power consumption is used as the evaluation indicator for the test. Moreover, the test is designed using the response surface test method to analyze the influence of cutters with different structure parameters as well as forward speed and cutter disk speed on the operation power consumption of the cutter disk. The cutter structure parameters are shown in Table 2.

Table 2 Cutter structure parameters

\begin{tabular}{lccc}
\hline Cutter disk combination & A & B & C \\
\hline Cut angle $\beta /\left(^{\circ}\right)$ & 130 & 140 & 150 \\
Bent angle $\alpha /\left(^{\circ}\right)$ & 40 & 50 & 60 \\
Working width $b / \mathrm{mm}$ & 182 & 156 & 133 \\
Cut angle $\beta /\left(^{\circ}\right)$ & 180 & 180 & 180 \\
Bent angle $\alpha /\left(^{\circ}\right)$ & 90 & 90 & 90 \\
Working width $b / \mathrm{mm}$ & 117.5 & 143 & 166 \\
\hline
\end{tabular}

According to the agronomic requirements of deep orchard fertilization and the actual production level, the response surface test method was used to set the 3 factors to 3 levels for simulation analysis. The factor level is shown in Table 3.

Table 3 Factors and level of operation power consumption simulation test

\begin{tabular}{cccc}
\hline & \multicolumn{3}{c}{ Factor } \\
\cline { 2 - 4 } Level & $\begin{array}{c}\text { Forward speed } \\
v / \mathrm{m}^{-1}\end{array}$ & $\begin{array}{c}\text { Cutter disk speed } \\
/ \mathrm{r} \cdot \mathrm{min}^{-1}\end{array}$ & $\begin{array}{c}\text { Cutter disk } \\
\text { combination }\end{array}$ \\
\hline-1 & 800 & 110 & $\mathrm{~A}$ \\
0 & 1150 & 130 & $\mathrm{~B}$ \\
1 & 1500 & 150 & $\mathrm{C}$ \\
\hline
\end{tabular}

3.4 Simulation results and analysis

In order to further judge the significance of the influence of each factor level on power consumption, the Design-expert software ${ }^{[26,27]}$ was used to perform fitting analysis and variance analysis on the test data in Table 4, so as to obtain the coding parameter regression equation of the influence of each test factor on trenching power consumption as follows:

$$
\begin{aligned}
& Y=31.59+6.81 X_{1}+0.66 X_{2}-3.60 X_{3}+1.63 X_{1} X_{2} \\
& +1.67 X_{1} X_{3}+4.09 X_{2} X_{3}+1.13 X_{1}^{2}-7.51 X_{2}^{2}+6.48 X_{3}^{2}
\end{aligned}
$$


Table 4 Simulation scheme and results of job power consumption

\begin{tabular}{|c|c|c|c|c|}
\hline \multirow[b]{2}{*}{$\begin{array}{c}\text { Test } \\
\text { number }\end{array}$} & \multicolumn{3}{|c|}{ Test factor } & \multirow{2}{*}{$\begin{array}{c}\text { Test index } \\
\text { Operation power } \\
\text { consumption } \\
Y / \mathrm{kW}\end{array}$} \\
\hline & $\begin{array}{c}\text { Forward } \\
\text { speed } \\
X_{1} / \mathrm{m} \cdot \mathrm{h}^{-1}\end{array}$ & $\begin{array}{l}\text { Cutter disk } \\
\text { speed } \\
X_{2} / \mathrm{r} \cdot \min ^{-1}\end{array}$ & $\begin{array}{c}\text { Cutter } \\
\text { combination } \\
X_{3}\end{array}$ & \\
\hline 1 & -1 & -1 & 0 & 18.39 \\
\hline 2 & 1 & -1 & 0 & 23.32 \\
\hline 3 & -1 & 1 & 0 & 26.01 \\
\hline 4 & 1 & 1 & 0 & 35.30 \\
\hline 5 & -1 & 0 & -1 & 25.62 \\
\hline 6 & 1 & 0 & -1 & 41.63 \\
\hline 7 & -1 & 0 & 1 & 40.05 \\
\hline 8 & 1 & 0 & 1 & 49.40 \\
\hline 9 & 0 & -1 & -1 & 24.69 \\
\hline 10 & 0 & 1 & -1 & 33.17 \\
\hline 11 & 0 & -1 & 1 & 36.19 \\
\hline 12 & 0 & 1 & 1 & 28.29 \\
\hline 13 & 0 & 0 & 0 & 27.10 \\
\hline 14 & 0 & 0 & 0 & 31.46 \\
\hline 15 & 0 & 0 & 0 & 36.11 \\
\hline 16 & 0 & 0 & 0 & 30.56 \\
\hline 17 & 0 & 0 & 0 & 32.70 \\
\hline
\end{tabular}

3.4.1 Regression model diagnosis

The normal probability of the operation power is analyzed using the Diagnostics function in the Design-expert software. The residual analysis represents the fitting degree effect, as shown in Figure 7. The normal plot of residuals of operation power is shown in Figure $7 \mathrm{a}$; the scatter diagram of predicted response vs. actual value is shown in Figure $7 b$. In Figure $7 a$, the internally standardized residuals are the abscissa, the normal probability is the

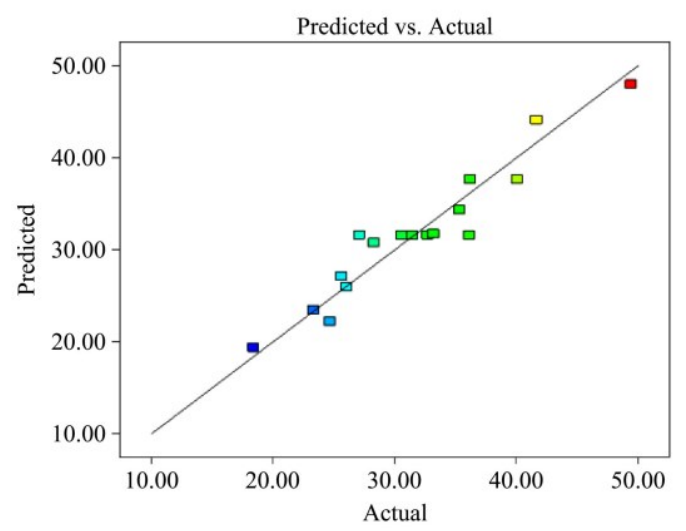

a. Normal plot of residuals of operation power

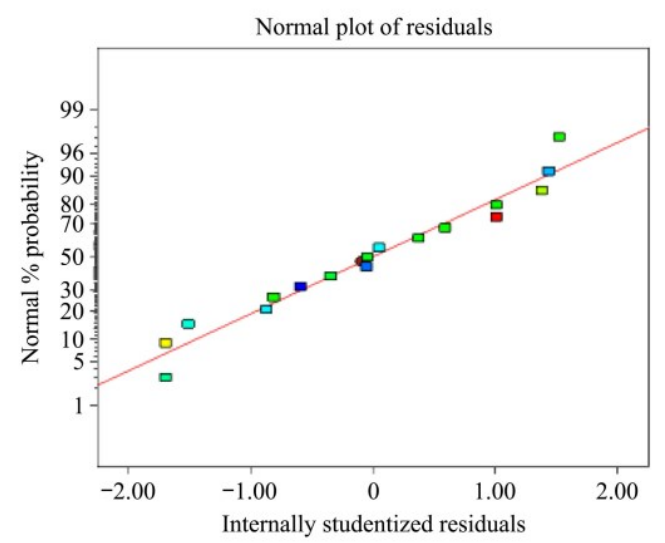

b. Scatter diagram of predicted response vs. actual value

Figure 7 Residual analysis of response indicators ordinate, and the residuals of power consumption are linear and have a high degree of fitting with the trajectory. In Figure $7 \mathrm{~b}$, the actual value is the abscissa, the predicted value represents the ordinate, the scatters are of the normal distribution, and the predicted scatter trajectory is close to a straight line, which proves the reliability of the regression model.

\subsubsection{Response surface analysis}

According to the analysis of variance of operation power consumption in Table 5 , the $p$-value of the model is extremely significant, and the item "lack of fit" is non-significant, indicating that the influence of each factor on trenching operation power consumption is significant and that the established model is in line with the actuality and can be used to predict the relationship between trenching operation power consumption and each influencing factor. The fitting degree coefficient of the model $R^{2}$ is 0.971 , indicating that the regression model has a high degree of fitting with the simulation test results and can be used to predict the operation power consumption variation in the trenching process. According to the $p$-value in Table 5, the influence of forward speed $X_{1}$ on operation power consumption is extremely significant, the interaction influence of cutter disk combination $X_{3}$, cutter disk speed $X_{2}$ and cutter speed $X_{3}$ and the influence of cutter disk speed square $X_{2}^{2}$ on operation power consumption are significant, and the interaction influence of cutter disk speed $X_{2}$, forward speed $X_{1}$ and cutter disk speed $X_{2}$ and the influence of forward speed square $X_{1}^{2}$ and cutter disk speed square $X_{2}^{2}$ on operation power consumption are non-significant. Therefore, the following equation can be obtained after removing "Non-significant" based on the analysis of variance of each factor on trenching operation power consumption:

$$
Y=31.59+6.81 X_{1}-3.60 X_{3}+1.67 X_{1} X_{3}+4.09 X_{2} X_{3}-7.51 X_{2}^{2}
$$

Table 5 Analysis of variance of operation power consumption

\begin{tabular}{ccccccc}
$\begin{array}{c}\text { Mutation } \\
\text { source }\end{array}$ & $\begin{array}{c}\text { Sum of } \\
\text { squares }\end{array}$ & $\begin{array}{c}\text { Degree of } \\
\text { freedom }\end{array}$ & $\begin{array}{c}\text { Mean } \\
\text { square error }\end{array}$ & $\begin{array}{c}F \\
\text { value }\end{array}$ & $\begin{array}{c}p \\
\text { value }\end{array}$ & Significant \\
\hline Model & 860.13 & 9 & 95.57 & 8.67 & 0.0047 & $* *$ \\
$X_{1}$ & 278.09 & 1 & 278.09 & 25.23 & 0.0015 & $* *$ \\
$X_{2}$ & 2.63 & 1 & 2.63 & 0.24 & 0.6401 & - \\
$X_{3}$ & 103.82 & 1 & 103.82 & 9.42 & 0.0181 & $*$ \\
$X_{1} X_{2}$ & 0.90 & 1 & 0.90 & 0.082 & 0.7831 & - \\
$X_{1} X_{3}$ & 11.09 & 1 & 11.09 & 1.01 & 0.3492 & - \\
$X_{2} X_{3}$ & 67.08 & 1 & 67.08 & 6.09 & 0.0430 & $*$ \\
$X_{1}^{2}$ & 1.48 & 1 & 1.48 & 0.13 & 0.7246 & - \\
$X_{2}^{2}$ & 65.00 & 1 & 65.00 & 5.90 & 0.0455 & $*$ \\
$X_{3}^{2}$ & 61.08 & 1 & 61.08 & 5.54 & 0.0508 & - \\
Residual & 77.15 & 7 & 11.02 & & & - \\
Lack of fit & 34.25 & 3 & 11.42 & 1.06 & 0.4575 & - \\
Error & 42.90 & 4 & 10.73 & & & \\
Total & 937.29 & 16 & & & & \\
variation & & & & & & \\
\hline Note & & & & &
\end{tabular}

Note: $p \leq 0.01$ means "extremely significant", marked as $* * ; 0.01<p \leq 0.05$ means "significant", marked as *; $p>0.05$ means "non-significant", marked as —.

The response surface plotted based on the trenching operation power consumption regression equation is shown in Figure 8. When the cutter disk combination is $B$, the trenching operation power consumption gradually increases as the cutter disk speed and the forward speed increase. When the cutter disk speed is less than $130 \mathrm{r} / \mathrm{min}$, it has a large influence on the trenching operation power consumption. When the cutter disk speed is $130 \mathrm{r} / \mathrm{min}$ and the forward speed is $1150 \mathrm{~m} / \mathrm{h}$, they have the largest influence on the trenching operation power consumption. When the cutter disk speed is greater than $130 \mathrm{r} / \mathrm{min}$ and the forward speed is greater 
than $1.15 \mathrm{~km} / \mathrm{h}$. Their influence on the trenching operation power consumption was small. As can be seen from the contour map, there was a relationship between the cutter disk speed and the forward speed; when the cutter disk speed $110 \mathrm{r} / \mathrm{min}<X_{1}<130 \mathrm{r} / \mathrm{min}$ and the forward speed $0.800 \mathrm{~km} / \mathrm{h}<X_{2}<1.150 \mathrm{~km} / \mathrm{h}$, the trenching operation power consumption is small.

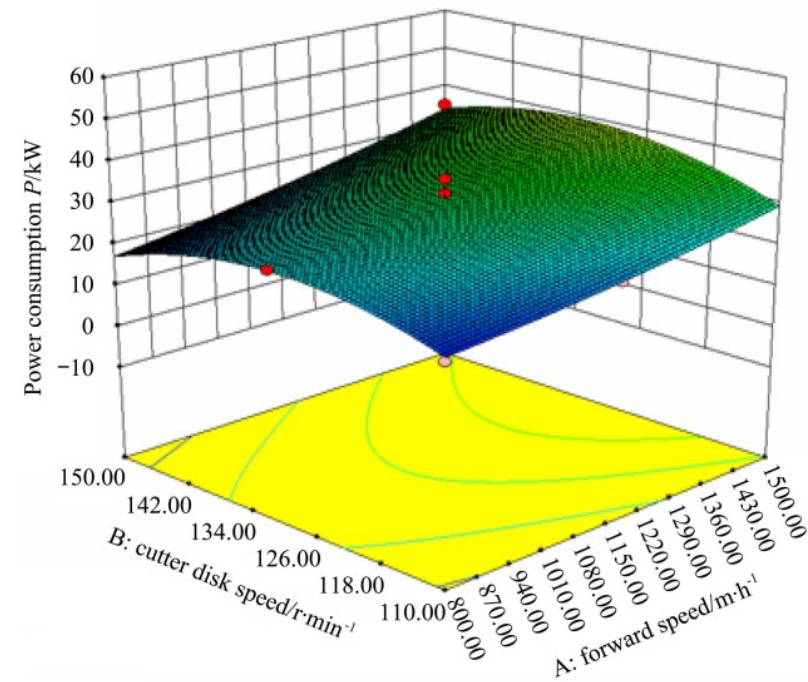

a. Response surface

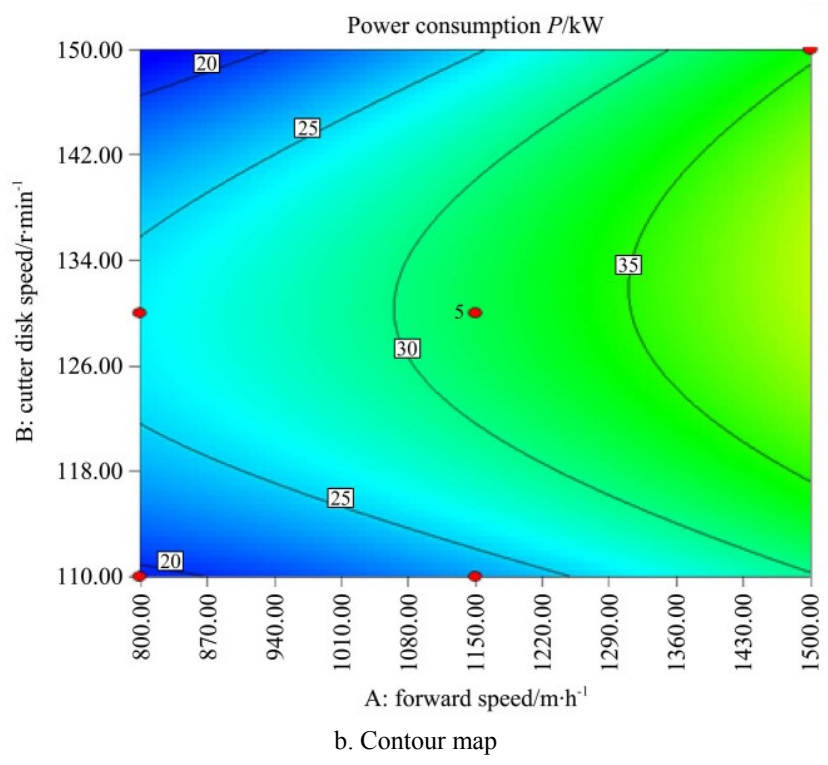

Figure 8 Influence of cutter disk speed and forward speed on power consumption in trenching operation

\section{Simulation optimization and test verification}

\subsection{Simulation optimization}

When the forward speed is $0.8-1.5 \mathrm{~km} / \mathrm{h}$, the cutter disk speed is $110-150 \mathrm{r} / \mathrm{min}$, and the cutter disk combination is $\mathrm{A}, \mathrm{B}$, and $\mathrm{C}$, the test factors need to be optimized in order to obtain the best test factor level. A mathematical model for optimization of parameters such as forward speed, cutter disk speed, and cutter disk combination was built. According to the test factor boundary conditions, the regression model was analyzed so as to obtain the mathematical model as follows:

$$
\max Y\left\{\begin{array}{l}
800 \leq X_{1} \leq 960 \\
110 \leq X_{2} \leq 150 \\
17 \leq Y\left(X_{1}, X_{2}\right) \leq 25
\end{array}\right.
$$

In the prospect of pursuing high efficiency and low energy consumption in agricultural machinery operations, the
"Optimization" function provided by the Design-Expert software was used to achieve the mechanical trenching operation indicator and small trenching operation power consumption and obtain the following influential factor parameters combination: forward speed of $0.815 \mathrm{~km} / \mathrm{h}$, cutter disk speed of $112 \mathrm{r} / \mathrm{min}$, cutter disk combination $C$, and trenching operation power consumption of $17.98 \mathrm{~kW}$.

\subsection{Test conditions}

In order to verify the optimization effect of the optimal influencing factor parameter combination obtained from simulation optimization, field verification experiments were carried out, and each set of tests was repeated 3 times. The tests were conducted at Wugong Village, Shihezi City, Xinjiang Region in August 2018. The three-year uncultivated land having the same soil physical properties as and a small difference from fruit planting land was selected as the test field. The average soil hardness was $2.16 \mathrm{MPa}$, the moisture content was $10.64 \%$, and the test area was $4.7 \mathrm{hm}^{2}$.

The test supporting power used a TN654 tractor. The test equipment included: trenching device, mechanical tachometer (Shanghai Tachometer Factory, measuring range 0-400 r/min), tape measure (Lianyungang Hongda Ruler Factory, measuring range 0-50 m), and NJTY3 agricultural machinery universal dynamic telemetry system. Figure 9 shows the field tests.

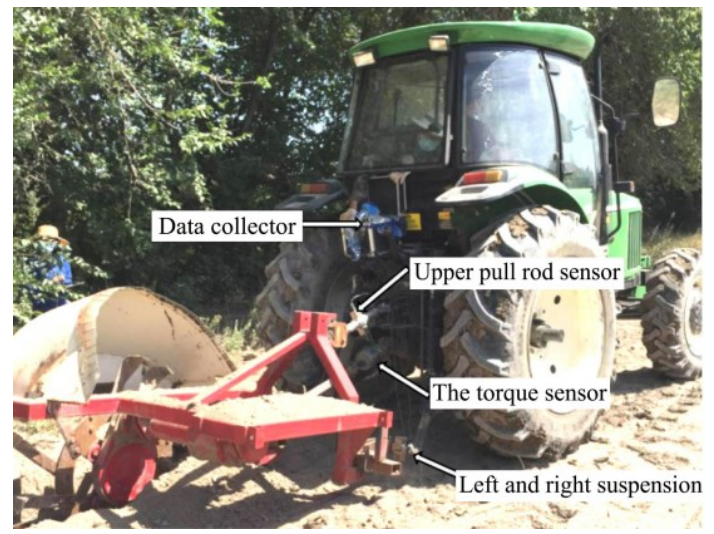

a. Installation chart of general dynamic telemeter for agricultural machinery

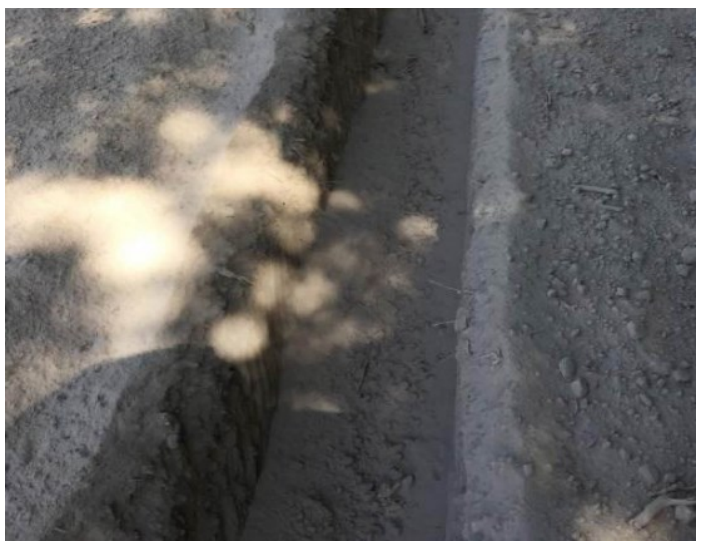

b. Fertilizer ditch opened

Figure 9 Field tests

\subsection{Test verification}

During the tests, a relatively flat test area of $50 \mathrm{~m}$ was selected, and it was divided into a $10 \mathrm{~m}$ preparation area and a $30 \mathrm{~m}$ data collection area. The forward speed could reach $0.8-1.5 \mathrm{~km} / \mathrm{h}$ under the control of the tractor. The output power of the tractor controlled the cutter disk speed, which could achieve unlimited speed regulation within the range of $0-160 \mathrm{r} / \mathrm{min}$. According to the trenching depth, the lifting frame of the hydraulic system could be controlled so as to achieve the required trenching depth. 
Through the tests, the trenching depth was $468 \mathrm{~mm}$, the width was $334 \mathrm{~mm}$, and the backfill thickness was $140 \mathrm{~mm}$. The test data were collected by the NJTY3 agricultural machinery universal dynamic telemetry system. According to the simulation test scheme record and calculation, the average of each set of tests was taken in the data collection area. The comparison between the test results and the simulation results is shown in Table 6.

Table 6 Analysis of variance of performance indicators

\begin{tabular}{cccc}
\hline Test count & $\begin{array}{c}\text { Theoretical value power } \\
\text { consumption } P_{1} / \mathrm{kW}\end{array}$ & $\begin{array}{c}\text { Test value power } \\
\text { consumption } P_{2} / \mathrm{kW}\end{array}$ & $\begin{array}{c}\text { Relative } \\
\text { error } / \%\end{array}$ \\
\hline 1 & 17.98 & 18.45 & 2.61 \\
2 & 17.98 & 18.20 & 1.22 \\
3 & 17.98 & 18.84 & 4.78 \\
5 & 17.98 & 18.55 & 3.17 \\
Mean & 17.98 & 18.72 & 4.12 \\
\hline
\end{tabular}

As shown in Table 6, the field test operation power consumption value is relatively higher than the theoretical value because additional power consumption was generated by field vegetation root systems, soil moisture content and unavoidable friction and wear in the operation process, the components such as frame, shroud, driving mechanism, etc. affecting the simulation efficiency were simplified in the simulation process, and the connecting parts such as bolts, gaskets, nuts, etc. were ignored. According to the comparison of the theoretical value with the field test value, the relative error mean is $3.18 \%$. This indicates that the built operation power consumption model has high engineering applicability for obtaining the actual trenching power consumption value, and provides a theoretical reference for selecting the parameter combination of a segmented cutting trenching device for saving power consumption.

\section{Conclusions}

In this study, in the EDEM software environment, the soil-ditching device interaction model was established, the response surface test was used to establish the mathematical model between the power consumption of the ditching operation and the experimental factors, and the working parameters (forward speed, cutter speed) and The influence of structural parameters (cutter head combination) on the power consumption of ditching operation were verified by field experiments, and the following conclusions were obtained:

1) Introduce the structure and working principle of the ditching device, analyze the power consumption of the ditching device by the unit method, and used MATLAB software to obtain a theoretical power consumption of $19.52 \mathrm{~kW}$ for the characteristics of Xinjiang soil and the structural parameters of the ditching transposition, which laid a theoretical foundation for simulation analysis.

2) On the basis of theoretical analysis, an interactive model of soil-ditching device was established using EDEM software, and the cutting process of the cutter head assembly was analyzed. The analysis showed that the operating power consumption gradually increased with time and then stabilized. The result is consistent with the theoretical analysis result.

3) In order to verify the reliability of the theoretical analysis and simulation analysis, a response surface test program was designed, and the working process of the trenching device was numerically simulated using EDEM software, and the working parameters (forward speed, cutter speed) and structural parameters (the model of the relationship between the cutter disk combination) and the power consumption of the trenching operation, and the model has a high degree of fit. The simulation results show that: the descending order of the influence of various factors on the operating power consumption is forward speed, cutter head combination, cutter head speed.

4) With the optimal work quality and minimum work power consumption as the fitting target, the best influencing factor parameters combination was obtained: the forward speed of $815 \mathrm{~m} / \mathrm{h}$, the cutter head speed of $112 \mathrm{r} / \mathrm{min}$, and with the cutter head combination $C$. Field tests were conducted with this value as working conditions. The test results showed that the average relative error between the theoretical power consumption value and the field test value was $3.18 \%$, which proved the accuracy of the discrete element simulation and optimization results.

\section{Acknowledgements}

This work was financially supported by the Shihezi University High-Level Talent Research Start-Up Project (rczk201917) and the Central Government Guided Local Science and Technology Development Special Fund Project (kc005104).

\section{[References]}

[1] National Bureau of Statistics of the People's Republic of China. China Statistical Yearbook. Beijing: China Statistics Press, 2020; pp.370-373. (in Chinese)

[2] Jiang N. Orchard full mechanization equipment. Contemporary Farm Machinery, 2019; 10: 59. (in Chinese)

[3] Zhang F. Do a good job in agricultural non-point source pollution prevention and control battle "one control, two reductions and three basics" goal refers to agricultural resources. China Agricultural Materials, 2015; 14: 3. (in Chinese)

[4] Asl J H, Singh S. Optimization and evaluation of rotary tiller blades: Computer solution of mathematical relations. Soil \& Tillage Research, 2009; 106(1): 1-7.

[5] Ucgul M, Fielke J M, Saunders C. Three-dimensional discrete element modelling of tillage: Determination of a suitable contact model and parameters for a cohesionless soil. Biosystems Engineering, 2014; 121(2) $105-117$.

[6] UMootaz, H R, Boyle J T. 3D dynamic analysis of soil-tool interaction using the finite element method. Journal of Terramechanics, 2003; 40(1): 51-62.

[7] Zhu J H, Li Z G, Zou J. The CAD system for rotary tiller blade design. Transactions of the CSAM, 1985; 26(3): 51-61. (in Chinese)

[8] Zhu X M. Research on power consumption of rotary tiller. Journal of Anhui Institute of Technology, 1986; 5(3): 121-133. (in Chinese)

[9] Zhu X M. Discuss with Zhu Jinhua and other comrades about CAD system of rotary tiller blade design. Journal of Agricultural Machinery, 1986; 4: 78-86. (in Chinese)

[10] Qin G L, Liao Q X, Zhou S X. Optimization design and analysis of power consumption of chain ditching machine based on MATLAB. Hubei Agricultural Sciences, 2009; 48(1): 210-214. (in Chinese)

[11] Zhang Q, Wang W, Liao J A. Design of fertilizing machine's furrow opener in jujube orchard and finite element analysis. Journal of Agricultural Mechanization Research, 2016; 38(4): 23-28. (in Chinese)

[12] Kang J M, Li S J, Yang X J, Liu L J, Li C R. Simulation analysis and experimental verification of power consumption of disc ditcher. Transactions of the CSAE, 2016; 32(13): 8-15. (in Chinese)

[13] Pan S Q. Optimal design and experimental research of core-shaft opener based on discrete element method. PhD dissertation. Changchun: Jilin University, 2015; 92p. (in Chinese)

[14] Tian D Y, Liu J D, Jiao H B. Optimization and analysis of working parameters of soil covering disc based on discrete element method. Journal of Agricultural Mechanization Research, 2018; 40(9): 16-22, 59. (in Chinese)

[15] Jia H L, Wang Q, Huang D Y. Design of bionic mole forelimb intelligent row cleaners. Int J Agric \& Biol Eng, 2019; 12(3): 27-35.

[16] Lin J, Zhang T J, Tian Y, Gao W Y, Qi L, Li B F. Optimization and 
experiment of biomimetic trenching device for returning straw in field. Transactions of the CSAM, 2018; 49(S1): 50-59, 67. (in Chinese)

[17] Bernacki H. Theory of rotary cultivators. Warsaw Institute of mechatronics. Research brief, N2, Warsaw, 1962; 2(1): 9-61.

[18] Department of Theoretical Mechanics, Harbin Institute of Technology. Theoretical mechanics. Higher Education Press, 2009; 389p. (in Chinese)

[19] Li J Q. Rotary ditching machine. Beijing: China Agricultural Machinery Press, 1984; 236p. (in Chinese)

[20] Li Y J, Wu T, Lin J H, Xu Y. Analysis of the motion characteristics of sand particles by the penetration cone based on discrete element method. Transactions of the CSAE, 2012; 28(24): 55-61.(in Chinese)

[21] Ucgul M, Fielke J M, Saunders C. Three-dimensional discrete element modelling (DEM) of tillage: Accounting for soil cohesion and adhesion. Biosystems Engineering, 2015; 129: 298-306.
[22] Ma Y J, Wang A, Zhao J G. Simulation analysis and experiment on drag reduction effect of convex blade subsoiler based on discrete element method. Journal of Agricultural Engineering, 2019; 35(3): 16-23. (in Chinese)

[23] Tamás K, Jóri I J, Mouazen A M. Modelling soil-sweep interaction with discrete element method. Soil \& Tillage Research, 2013; 134(8): 223-231.

[24] Braja M D. Advanced soil mechanics. Taylor \& Francis, 2008; 600p.

[25] Fielke J M. Interactions of the cutting edge of tillage implements with soil. Journal of Agricultural Engineering Research, 1996; 63(1): 61-71.

[26] Li Y Y, Hu C R. Experimental design and data processing. Beijing: Chemical Industry Press, 2008; 257p. (in Chinese)

[27] Ren L Q. Experimental design and optimization. Beijing: Science Press, 2009; 259p. (in Chinese) 